Rheumatoid Arthritis (RA) patients up to 50 years old supported by a charity program of the Belgian French speaking radio-television (RTBF).

Objectives: The objectives of this cohort are to observe if a tight control favour remission at 6 months and to define synovial markers for severy and response to therapy.

Methods: RA patients fulfilling the ACR/EULAR 2010 criteria and naïve to DMARDs therapy were recruited. Synovial biopsies before treatment were obtained using an ultrasound guided needle biopsy (US-NB) of the small joints or miniarthroscopy of the knee. RA disease activity measures including DAS28CRP domains were evaluated every 3 months and treatment was adapted by the treating physician. Tissues were assessed for quality. Retrieved tissue was fixed, stained and paraffin embedded for blinded tissue pathotype description.

Results: A synovial biopsy was performed in 37 patients using US-NB in $n$ patients. Patients were classified according 4 types of synovial histopathology findings. Baseline characteristics of the cohort is summarized in table 1. All patients in the diffuse lymphoïd group were ACPA negative and the majority of the ACPA positive patients were classified in the pauci immune and fibrous group. As shown in figure 1, the pauci immune ERA group showed lower DAS28-CRP response than the other groups.

\begin{tabular}{lllll} 
Table 1 & \multicolumn{1}{l}{ All patients } & $\begin{array}{l}\text { Group } \\
\mathrm{n}=37\end{array}$ & $\begin{array}{l}\text { Group 'Nodules' } \\
\mathrm{n}=7\end{array}$ & $\begin{array}{l}\text { Group } \\
\text { 'Pauci- } \\
\text { Immun' } \\
\end{array}$ \\
& & & & $\begin{array}{l}\text { 'Fibrous' } \\
\mathrm{n}=13\end{array}$ \\
\hline Age mean (SD) & $34.4( \pm 1.9)$ & $31.3( \pm 2.9)$ & $36.1( \pm 4.4)$ & $33.0( \pm 5.8)$ \\
Gender & $30 \mathrm{~F} / 7 \mathrm{M}$ & $14 \mathrm{~F} / 3 \mathrm{M}$ & $5 \mathrm{~F} / 2 \mathrm{M}$ & $11 \mathrm{~F} / 2 \mathrm{M}$ \\
ACPA \% $(\mathrm{n}=)$ & $37.8 \%(\mathrm{n}=14)$ & $0 \%(\mathrm{n}=0)$ & $57.1 \%(\mathrm{n}=4)$ & $76.9 \%(\mathrm{n}=10)$ \\
RF \% $(\mathrm{n}=)$ & $48.6 \%(\mathrm{n}=18)$ & $11.8 \%(\mathrm{n}=2)$ & $85.7 \%(\mathrm{n}=6)$ & $76.9 \%(\mathrm{n}=10)$ \\
Erosion \% ( $\mathrm{n}=)$ & $35.1 \%(\mathrm{n}=13)$ & $17.6 \%(\mathrm{n}=3)$ & $57.1 \%(\mathrm{n}=4)$ & $38.4 \%(\mathrm{n}=5)$ \\
Baseline DAS28- & $4.60( \pm 0.23)$ & $4.52( \pm 1.50)$ & $5.00( \pm 1.37)$ & $4.76( \pm 1.44)$ \\
CRP & & & & \\
\hline
\end{tabular}
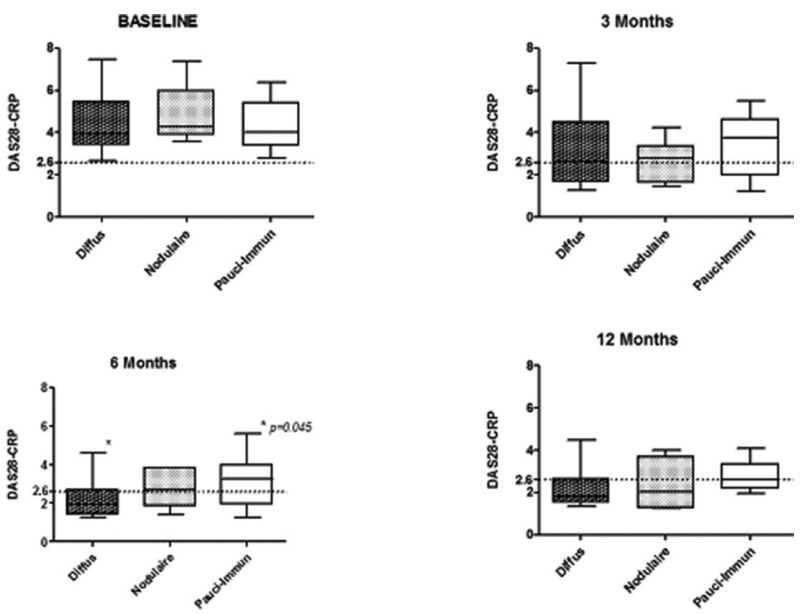

Conclusions: Synovial tissue analysis could provide a step change towards personalized medicine in daily clinical practice for disease stratification and treatment selection of ERA. In the CAP48 cohort, a high number of these young and ERA patients achieved remission at 6 months but a lower response was observed in the pauci immune group. Further analyses are ongoing to define individual synovial markers of severity and response.

Disclosure of Interest: None declared

DOI: 10.1136/annrheumdis-2018-eular.5207

\section{FRI0647 ESTIMATION OF MINIMUM CLINICALLY IMPORTANT DIFFERENCE IN FIBROMYALGIA FOR FIQR USING BPI AS THE ANCHOR MEASURE}

S. Surendran ${ }^{1}$, C. B. Mithun ${ }^{1} .{ }^{1}$ Rheumatology, Amrita Institute of Medical Sciences, Kochi, India

Background: The FIQ (Fibromyalgia Impact Questionnaire) was first published in 1991 and had 19 items which were recalled over a week. The scoring system is highly reliable and is recognised as an outcome measure that covers the multiple domains of Fibromyalgia ${ }^{1}$. A prior study by Benett et $\mathrm{al}^{2}$ have shown that $14 \%$ change in the FIQ total score represents the Minimum Clinically Important Difference(MCID) in the Fibromyalgia. The FIQ was revised in 2009 to the 20 item
Fibromyalgia Impact Questionnaire Revised or FIQR. However, there has been no study done for assessing the MCID of the FIQR in Fibromyalgia.

Objectives: The aim of our study is to estimate the MCID for Fibromyalgia Impact Questionnaire Revised using anchor-based methodology with average pain score on Brief Pain Inventory as the anchor.

Methods: We have used data from our prospectively followed cohort of fibromyalgia patients. They were treated as per protocol with duloxetine in escalating doses. Data from this cohort was used to estimate the MCID for the FIQR using anchor-based methodology The anchor used was the average pain score on Brief Pain Inventory(BPI). The MCID for BPI average pain score was calculated by Mease et al to be $30 \%{ }^{3}$. Thus, all patients in our cohort having an improvement of greater than $30 \%$ were classified as responders. All other patients were non-res ponders. Within these two groups, the means and standard deviations of the FIQR scores at baseline and at the end of treatment were obtained. The MCID was calculated as the difference in the unadjusted mean change in the FIQR scores between the "non-responder" group and the group with "responder group". It was also expressed as a percentage reduction from the mean baseline FIQR.

Results: Table 1 shows the mean and standard deviation of FIQR scores at baseline, endpoint and the mean change along with the calculated MCID. Table 1

\begin{tabular}{llllll}
\hline $\begin{array}{l}\text { Anchor } \\
\text { status }\end{array}$ & $\begin{array}{l}\text { No. of } \\
\text { patients }\end{array}$ & $\begin{array}{l}\text { Baseline Mean } \\
\pm \text { SD }\end{array}$ & $\begin{array}{l}\text { Endpoint mean } \\
\pm \text { SD }\end{array}$ & $\begin{array}{l}\text { Mean change } \pm \\
\text { SEM }\end{array}$ & MCID \\
\hline Responder & 58 & $58.50 \pm 19.03$ & $26.62 \pm 14.76$ & $31.88 \pm 2.53$ & 27.04 \\
Non- & 18 & $62.17 \pm 16.97$ & $57.33 \pm 13.00$ & $4.83 \pm 3.75$ & \\
respond & & & & &
\end{tabular}

responders

Conclusions: Based on our data, we suggest that a "27.04 point" or " $45.5 \%$ " improvement on the FIQR score represents the minimum clinically important dif ference for FIQR in fibromyalgia patients presenting with moderate to severe pain. Strengths of this work include the usage of prospectively followed patient population for analysis, protocol-based treatment with duloxetine and representation of a local population which more is applicable to our clinical practice. That MCID obtained for the FIQR score is much higher than the $14 \%$ which was the MCID obtained for the older FIQ score may suggest a population-based variation in improvement of outcome measures.

\section{REFERENCES:}

1. Williams DA, Arnold LM. Measures Applied to the Assessment of Fibromyalgia. Arthritis Care Res. 2011;63(2):1487-1495. doi:10.1002/acr.20531. Measures

2. Bennett RM, Bushmakin AG, Cappelleri JC, Zlateva G, Sadosky AB. Minimal clinically important difference in the fibromyalgia impact questionnaire. J Rheumatol. 2009;36(6):1304-1311. doi:10.3899/jrheum.081090

3. Mease PJ, Spaeth M, Clauw DJ, et al. Estimation of minimum clinically important difference for pain in fibromyalgia. Arthritis Care Res. 2011;63 (6):821-826. doi:10.1002/acr.20449

Acknowledgements: We would like to acknowledge and thank the statistical assistance provided by Mrs Renjitha Bhaskaran from the Department of Biostatistics at Amrita Vishwavidyapeetham University.

Disclosure of Interest: None declared

DOI: 10.1136/annrheumdis-2018-eular.5492

\section{FRI0648 DIRECTLY COMPARING LATENT FUNCTIONAL ABILITY IN ADOLESCENTS WITH JIA USING THE CHAQ AND HAQ: AN ITEM RESPONSE THEORY ANALYSIS}

S. J. W. Shoop-Worrall ${ }^{1,2}$, M. O. Voshaar ${ }^{3}$, M. van de Laar ${ }^{3,4}$, W. Thomson ${ }^{1,2}, \mathrm{~K}$. L. Hyrich ${ }^{1,2}$, J. E. McDonagh ${ }^{1,2}$, S. M. M. Verstappen ${ }^{1,2}$ on behalf of CAPS. ${ }^{1}$ The University of Manchester, ${ }^{2}$ Manchester Foundation Trust, Manchester, United Kingdom, ${ }^{3}$ Department of Psychology, Health \& Technology, University of Twente, ${ }^{4}$ Department of Rheumatology, Medisch Spetrum Twente, Enschede, Netherlands

Background: Measuring and comparing functional ability in adolescents with JIA is challenging due to the use of multiple questionnaires, including the proxy completed Childhood Health Assessment Questionnaire (P-CHAQ), the adoles cent version (A-CHAQ) and the Health Assessment Questionnaire (HAQ).

Item response theory (IRT) allows items on multiple questionnaires to be linked to an underlying continuous variable. This allows scores to be corrected for characteristics of the administered items, thus making them comparable between different questionnaires. Recently, a common reporting metric for functional ability was developed in a combined dataset of 16386 patients with various inflammatory rheumatic diseases, including 1029 paediatric patients with JIA.

Objectives: i) To cross-validate the item response models using three functional ability questionnaires in adolescents with JIA. ii) To assess agreement between overall function scores obtained from the different questionnaires.

Methods: Adolescents aged 11 to 17 with JIA were enrolled to a UK, multicentre inception cohort, the Childhood Arthritis Prospective Study (CAPS). In a sub- 